
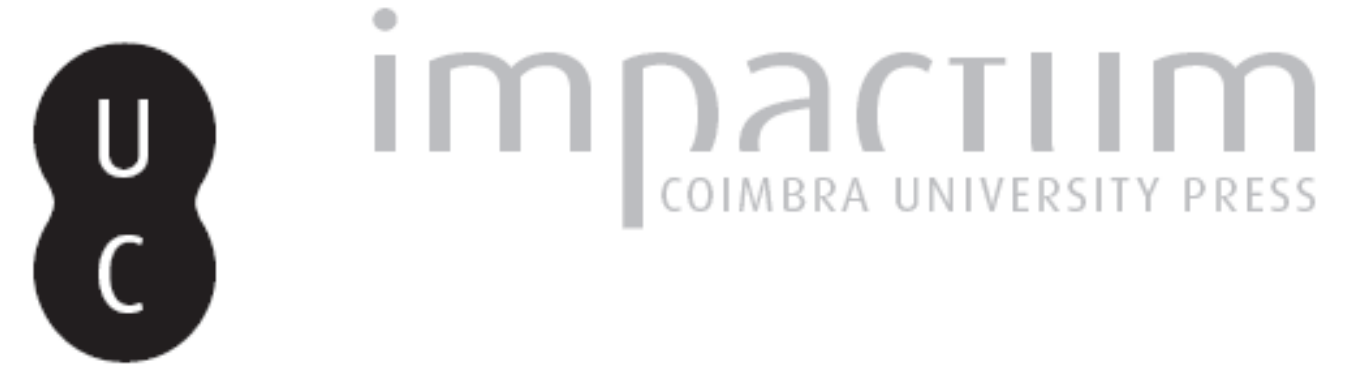

\title{
Direitos dos transgêneros sob a perspetiva europeia
}

Autor(es): Cunha, Leandro Reinaldo da

Publicado por: Imprensa da Universidade de Coimbra

URL persistente:

URl:http://hdl.handle.net/10316.2/43678

DOI:

DOI:https://doi.org/10.14195/1647-6336_19_4

Accessed : $\quad$ 26-Apr-2023 15:50:29

A navegação consulta e descarregamento dos títulos inseridos nas Bibliotecas Digitais UC Digitalis, UC Pombalina e UC Impactum, pressupõem a aceitação plena e sem reservas dos Termos e Condições de Uso destas Bibliotecas Digitais, disponíveis em https://digitalis.uc.pt/pt-pt/termos.

Conforme exposto nos referidos Termos e Condições de Uso, o descarregamento de títulos de acesso restrito requer uma licença válida de autorização devendo o utilizador aceder ao(s) documento(s) a partir de um endereço de IP da instituição detentora da supramencionada licença.

Ao utilizador é apenas permitido o descarregamento para uso pessoal, pelo que o emprego do(s) título(s) descarregado(s) para outro fim, designadamente comercial, carece de autorização do respetivo autor ou editor da obra.

Na medida em que todas as obras da UC Digitalis se encontram protegidas pelo Código do Direito de Autor e Direitos Conexos e demais legislação aplicável, toda a cópia, parcial ou total, deste documento, nos casos em que é legalmente admitida, deverá conter ou fazer-se acompanhar por este aviso.

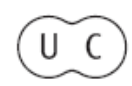


DEBATER

A EUROPA

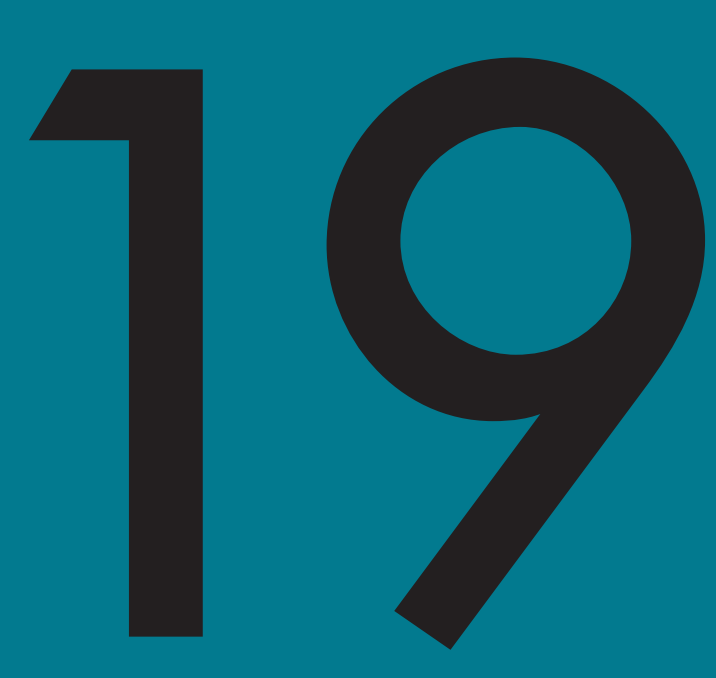

jul-dez 2018

QUE DESAFIOS À CIDADANIA EUROPEIA NO SÉCULO XXI?

WHAT CHALLENGES TO EUROPEAN

CITIZENSHIP IN THE 21ST CENTURY? 


\title{
Direitos dos transgêneros sob a perspetiva europeia
}

\author{
Transgender's rights under European view
}

Leandro Reinaldo da Cunha

Universidade Federal da Bahia

leandroreinaldodacunha@gmail.com

\section{Resumo}

O reconhecimento do ser humano como o elemento mais importante da humanidade e o pleno respeito a todas as suas características individualizadoras é preponderante para a consolidação da cidadania e de uma sociedade que tem nos direitos humanos o seu lastro, razão pela qual a atenção aos direitos da população transgênero se faz imprescindível. Entender a perspectiva do continente europeu sobre o tema é primordial, mormente ante a sua capacidade de polinizar seu pensar para todo o planeta. Para o presente trabalho utiliza-se da pesquisa bibliográfica, valendo-se do método científico-dedutivo.

Palavras-chave: Identidade de gênero, Transgênero, Corte Europeia de Direitos Humanos, Dignidade da pessoa humana, Direitos humanos.

\section{Abstract}

The recognition of the human being as the most important element of mankind and the full respect to all their individualizing characteristics is preponderant to citizenship consolidation and to a society based on human rights, reason why attention to the rights of transgender people is indispensable. Understanding the European continent vision on this theme is primordial, especially when faced with the capacity to pollinate its thinking and spread it to all around the world. In order to produce this paper, bibliographical research procedures based on the scientific-deductive method were employed.

Keywords: Gender identity, Transgender, European Court of Human Rights, Human dignity, Human rights. 


\section{Introdução}

O reconhecimento da sexualidade como elemento constituinte da personalidade do ser humano, bem como a sua constituição como um parâmetro nuclear do desenvolvimento da sociedade é uma percepção que se faz consolidada no continente europeu, que apresenta uma consciência da necessidade de atenção a tal preceito como primordial para a prevalência e respeito dos direitos humanos.

Nessa seara específica ganha contornos peculiares a questão do respeito aos direitos da população transgênero, sendo uma questão que ganhou a atenção de nações europeias em meados do século passado, enquanto o tema ainda é discutido de forma bastante rara nas Américas, com alguns poucos países tendo legislação específica sobre o tema.

O respeito à dignidade da pessoa humana é primordial para que se possa constatar o nível de cidadania de cada nação, sendo possível se afirmar que seu nível de evolução social pode ser aferido segundo a maneira pela qual ela trata seus cidadãos inseridos na categoria de minorias, como é o caso dos transgêneros.

Tendo por base a consciência de que a União Europeia apresenta um conjunto de países com características distintas, ainda que apresentem similaridades entre si, sem, tampouco se olvidar que nem todos os países que compõem a Europa fazem parte da União Europeia, é importante se consignar que inexiste uma legislação uniforme ou comum sobre o tema.

O presente artigo, valendo-se do método científico-dedutivo de pesquisa bibliográfica, tem por objetivo trazer uma visão panorâmica da atenção aos transgêneros na Europa, tendo por base as características que envolvem a proteção a esse grupo específico, como a previsão de reconhecimento legal da identidade de gênero, possibilidade de mudança de nome e indicação de gênero nos documentos, necessidade de constatação clínica da transexualidade ou intervenção cirúrgica prévia para o reconhecimento de direitos e restrições etárias.

\section{Identidade de gênero}

A sexualidade manifesta-se como um dos elementos caracterizadores da individualidade humana, presente de forma contínua no cotidiano de todo indivíduo, nas mais diversas situações, das mais coloquiais (como a definição de qual casa de banho o sujeito pode usar) até situações de alta complexidade (acesso a direitos fundamentais), razão pela qual a compreensão adequada do tema se faz preponderante.

Um dos elementos mais perniciosos à garantia dos direitos das pessoas é a ignorância acerca dos preceitos fundamentais que regem aquele tema específico e quando o assunto é a sexualidade o desconhecimento é uma constante. 
Em uma análise superficial é possível se afirmar que a sexualidade é composta por quatro elementos distintos, quais sejam, o sexo, o gênero, a orientação sexual e a identidade de gênero, sendo certo que a perfeita compreensão de cada conceito é indispensável para que se possa tratar de forma minimamente adequada das questões inerentes ao tema.

O primeiro dos conceitos a ser apreciado é o sexo, que tecnicamente há de ser entendido como a configuração física ou morfológica constatada no momento do nascimento da pessoa, a qual pode ser inserida na condição binária de homem ou mulher. No mais das vezes essa verificação se mostra fácil, contudo existe um número considerável de pessoas no mundo cuja constatação segundo tal parâmetro se mostra extremamente delicada, considerando que, em dados publicados no ano de 2.000 , pode ser superior a $2 \%$ a variante do ideal binário macho/fêmea, sendo que entre um e dois a cada mil desses casos realiza alguma cirurgia em decorrência dessa desconformidade'.

O segundo dos elementos da sexualidade a ser considerado é o gênero, o qual pode ser entendido como a representação social do indivíduo segundo os parâmetros do masculino ou feminino, originado de uma elaboração cultural, numa "construção de fundo sociológico e absolutamente subjetiva, muito mais conectada com o papel que o indivíduo desempenha na sociedade do que com suas características físicas ou genéticas"2.

Em seguida se faz pertinente discorrer sobre a orientação sexual, conceito que caracteriza-se pelo interesse ou atração sexual sentida pelo indivíduo, sendo preponderante se consignar que não se trata de uma escolha ou opção do sujeito, mas sim de uma condição inata, ou decorrente de fatores biológicos ou psicossociais ${ }^{3}$. Nesse âmbito se costuma identificar, de forma mais genérica, quatro grupos, quais sejam: heterossexual (interesse destinado a pessoa de gênero distinto), homossexual (atração por alguém do mesmo gênero), bissexual (desejo sexual tanto por pessoas do mesmo gênero quanto de gênero distinto) e assexual (não há a manifestação de interesse sexual por nenhum dos gêneros).

Finalmente, para concluir a compreensão do contexto da sexualidade há de se tratar da identidade de gênero, que revela a percepção de pertencimento do indivíduo quanto ao seu gênero, sendo possível se classificar o sujeito como cisgênero (aquele que apresenta identidade de gênero compatível com o sexo assinalado em seu nascimento) e transgênero (pessoa cujo sexo indicado no nascimento se mostra em conflito com a sua percepção de gênero), grupo no qual se pode inserir o transexual, enquadrado atualmente na previsão de disforia de gênero (Código 302 do Manual Diagnostico e Estatístico de Transtornos Mentais - DSMV) da Associação Americana de Psiquiatria (American Psychiatric Association - APA), bem como no Código Internacional de Doenças (CID - F64.0).

1 BlaCKleSs, M., CHARUVASTRA, A., DERrYCK, A., FAUSTO-STERling, A., LAUZANNE, K. and LEE, E. (2000), How sexually dimorphic are we? Review and synthesis. American Journal of Human Biology, vol. 12, p. 151-166, 2000. ISSN 1520-6300.

2 CUNHA, Leandro Reinaldo da. Identidade e redesignação de gênero: Aspectos da personalidade, da família e da responsabilidade civil. Rio de Janeiro: Lumen Juris, 2015, p. 25. ISBN 978-85-8440-206-9

3 CUNHA, Leandro Reinaldo da. Identidade e redesignação de gênero: Aspectos... p. 38-39. 
Nunca é bastante se afirmar que um dos grandes problemas da compreensão das questões vinculadas à sexualidade está na confusão entre os conceitos de orientação sexual e identidade de gênero, sendo certo que o cisgênero e o transgênero podem apresentar qualquer uma das orientações sexuais possíveis, conforme apresentado anteriormente.

Dessa forma a adequada compreensão dos conceitos que permeiam a sexualidade é imprescindível para que se possa estabelecer qualquer sorte de discussão que tenha por base a sexualidade.

\section{Visão Europeia quanto à identidade de gênero}

Face ao fato de ser um dos lugares do mundo no qual a questão da identidade de gênero já vem sendo discutida há tempos é de se entender que o tema se mostra consolidado de forma transnacional na Europa, com algum tipo de tratamento em quase todos os países que compõem o continente, o que permite se estabelecer uma visão panorâmica da realidade da comunidade transgênero na região sob a perspectiva jurídica.

Partindo-se de uma análise genérica do tema nas mais diversas nações do continente europeu é possível se verificar alguns aspectos que são os preponderantes para a discussão da identidade de gênero na região, criando um espectro básico de compreensão da questão na Europa.

Inicialmente constata-se que há um reconhecimento bastante amplo da necessidade de se cuidar da questão da identidade de gênero na Europa, considerando-se que se verifica que boa parte dos países (41 deles) estabelecem em seu ordenamento algum sorte de procedimento legal para o reconhecimento da identidade de gênero, enquanto apenas 2 países proíbem (Chipre e Liechtenstein).

Dentre os direitos mais elementares que os transgêneros querem ver atendidos estão a possibilidade de adequação do nome e dos documentos de acordo com a sua identidade de gênero, uma consequência elementar do reconhecimento da sua condição sexual, visando gerar uma compatibilidade entre a sua representação social e os dados consignados em seus documentos de identificação pessoal.

De se notar que em quase todos os países europeus há a possibilidade da mudança do nome e indicação de gênero nos documentos, situação bastante distinta da que se encontra na América do Sul, por exemplo, onde algumas nações apresentam legislação sobre o tema (Argentina - Lei 26.743 de 2012 e Uruguai - Lei 18.620 de 2009) enquanto outros, como o Brasil, não trazem legislação expressa sobre o tema mas tem autorizado a adequação por meio do Poder Judiciário, com posicionamento favorável dos Tribunais Superiores ${ }^{4}$.

4 CUNHA, Leandro Reinaldo da. Identidade de gênero sob a atual perspectiva dos tribunais superiores. a possibilidade da mudança de nome e gênero nos documentos independentemente da realização de procedimentos cirúrgicos prévios. $R T$ vol. 986 2017, p. 111-125. ISSN 0034-9275 
De se consignar que em $1^{\circ}$ de março de 2018, em decisão dotada de efeito erga omnes e com força vinculante, o Supremo Tribunal Federal (STF) julgou a ADI 4275 e estabeleceu que a mudança de prenome e sexo nos documentos do transgênero independe da realização de qualquer intervenção cirúrgica prévia, a qual pode ser requerida de forma administrativa, diretamente perante o Cartório competente, independentemente de análise do Poder Judiciário.

Ponto crucial para a apreciação da questão no continente europeu está vinculado à necessidade de qualquer constatação clínica da condição de transexual ou intervenção cirúrgica prévia para a concessão dos benefícios legais decorrentes do reconhecimento da identidade de gênero distinta do sexo consignado quando do nascimento da pessoa.

Em números pode-se considerar que dos 41 países que preveem o reconhecimento da identidade de gênero 20 deles exigem a realização de esterilização prévia, 36 determinam a apresentação de diagnóstico médico e 23 impõem a realização de divórcio caso o requerente seja casado.

Apenas para se estabelecer um parâmetro comparativo, no Brasil, em que pese não haver legislação específica sobre o tema, não há a exigência de esterilização para o reconhecimento da identidade de gênero por parte dos tribunais, tampouco há qualquer menção específica quanto ao estado civil do requerente. Todavia no que tange à necessidade de diagnóstico médico este tem sido requerido, ainda que não se exija a realização de qualquer sorte de tratamento cirúrgico ou hormonal prévio, como se pode constatar da decisão proferida pelo Superior Tribunal de Justiça (STJ) em $2017^{5}$.

No quanto tange ao critério etário verifica-se que em 34 países pessoas com menos de 18 anos não tem acesso à mudança legal de gênero e seus consectários legais. Nesse quesito, ainda tendo o Brasil como parâmetro comparativo, verifica-se que há o estabelecimento de que as intervenções cirúrgicas apenas ocorram após os 21 (vinte e um) anos (Resolução CFM n 1.955/2010 e Portaria n 2.803, de 19 de novembro de 2013 do Ministério da Saúde), sendo a hormonoterapia autorizada a partir dos 18 anos (mesma Portaria do Ministério da Saúde), havendo, contudo, um parecer consultivo do Conselho Federal de Medicina que entende ser admissível o início do tratamento hormonal nos primeiros sinais de puberdade a fim de promover o bloqueio da puberdade do gênero de nascimento (Consulta CFM 32/12 - Parecer CFM 08/13).

Ressalta-se que tais dados estatísticos aqui indicados são baseados em levantamento do Transgender Europe ${ }^{6}$ e apenas tem por objetivo indicar como a questão da identidade de gênero é tema presente na percepção europeia dos direitos humanos. Contudo compreensão da questão passa necessariamente pelo posicionamento adotado pela Convenção

$5 \quad$ STJ, REsp 1.626.739, $4^{\mathrm{a}}$ Turma, Rel. Min. Luis Felipe Salomão

6 http://tgeu.org/wp-content/uploads/2017/05/Index-online.png 
Europeia de Direitos Humanos, bem como pelas decisões proferidas pela Corte Europeia de Direitos Humanos sobre o tema.

Quanto às questões acima apresentadas existem entendimentos de grande importância e que se fazem cogentes para os países vinculados à Convenção Europeia de Direitos Humanos. No que tange à questão da necessidade de realização de esterilização prévia a fim de viabilizar o acesso a direitos inerentes à condição de transexual imposta por vários países (atualmente 20 deles) esta foi definida como algo que viola os direitos humanos pela Corte Europeia de Direitos Humanos em abril de 2017, o que determina que todos os estados membros devam adequar suas legislações nesse sentido.

A Corte Europeia de Direitos Humanos ao analisar três processos promovidos em face da França posicionou-se no sentido de que requerer a esterilização forçada e ter a infertilidade como um requisito para o acesso aos direitos inerentes ao reconhecimento da identidade de gênero (A.P. vs França) ofenderiam o art. 8 da Convenção Europeia de Direitos Humanos (direito ao respeito à vida privada), bem como não seria admissível a exigência da realização de exames médicos obrigatórios impostos pelo Tribunal (E. Garçon vs França), nem mesmo a imposição de diagnóstico de saúde mental (A.P. vs France), entendendo que tais imposições seriam contrárias à Convenção.

A perspectiva é a de que a imposição da realização de um diagnóstico de saúde mental prévio ao reconhecimento legal da identidade de gênero seria uma violação aos direitos humanos e à dignidade das pessoas transgênero, com o condão de promover estigma, exclusão social e discriminação ${ }^{7}$, como asseverou Julia Ehrt, diretora executiva da TGEU.

Evidencia-se que o conteúdo da Convenção Europeia de Direitos Humanos tem por escopo a proteção de toda e qualquer pessoa, independentemente de suas características personalizadoras, não sendo plausível a restrição a direitos a quem quer que seja em razão de parâmetros vinculados a sua sexualidade. Conforme preconiza o art. 14 da referida convenção

Art. 14. El goce de los derechos y libertades reconocidos en el presente Convenio ha de ser asegurado sin distinción alguna, especialmente por razones de sexo, raza, color, lengua, religión, opiniones políticas u otras, origen nacional o social, pertenencia a una minoría nacional, fortuna, nacimiento o cualquier otra situación.

Outra luta que se estabelece atualmente é no sentido de se despatologizar a condição do transexual, por meio de uma reforma na classificação internacional de doenças. O objetivo é que se reconheça que o fato de apresentar uma identidade de gênero distinta do sexo assinalado no momento do nascimento não caracteriza uma patologia, mas apenas uma condição pessoal relacionada à sexualidade.

7 https://tgeu.org/idahot_forum_map-launch/ 
$\mathrm{Na}$ atual revisão da Classificação Internacional de Doenças (CID-11) sob análise da Organização Mundial da Saúde há a proposta de que tal posicionamento seja seguido, fazendo com que a identidade de gênero incongruente com a indicação de sexo consignada no nascimento não mais figure como uma doença mas sim meramente como uma condição relacionada à saúde sexual, não mais a rotulando como uma doença mental.

A questão é relevante e gera uma série de considerações. Em muitos lugares é necessária a configuração da previsão consignada nos parâmetros da Classificação Internacional de Doenças (CID) para que o sujeito tenha acesso a tratamento médico subvencionado pelo Estado, como acontece no Brasil com base na Portaria n ${ }^{\circ} 2.803$, de 19 de novembro de 2013 do Ministério da Saúde.

. De se ressaltar que em alguns países europeus a transexualidade não mais é considerada como uma doença, como ocorre na França que, por meio do decreto $n^{0}$ 2010-125 de 08 de fevereiro de 2010, retirou tal condição da listagem de patologias psiquiátricas, da mesma forma que se posiciona o Standards of Care (SOC) for the Health of Transexual, Transgender, and Gender Nonconforming People, que entende que a transexualidade é apenas uma questão de diversidade ${ }^{8}$.

Assim verifica-se que há uma real preocupação com a questão da sexualidade no continente europeu, especialmente no que tange à questão da identidade de gênero na perspectiva dos direitos humanos, sendo considerado elemento preponderante para o estabelecimento e consolidação da cidadania para todos os cidadãos.

\section{Considerações finais}

A preocupação com o bem estar e desenvolvimento de todo ser humano é uma condição básica a toda e qualquer nação que tenha os direitos humanos como um parâmetro relevante em seu ordenamento jurídico, mormente se houver a consciência elementar de que não há como se pensar em nenhuma forma de sociedade sem o homem.

O posicionamento adotado no continente europeu com relação à identidade de gênero se mostra bastante confluente com o entendimento de que o ser humano, os direitos da personalidade e a dignidade da pessoa humana são conceitos muito caros ao ordenamento jurídico da região.

Entender a relevância do tema e exigir que, por meio de entidades internacionais dotadas de poder regional, os países adaptem seus procedimentos e suas legislações visando atender aos interesses e necessidades da comunidade transgênero é passo preponderante para uma sociedade mais próxima dos preceitos humanísticos que regem os princípios norteadores dos direitos humanos.

8 CUNHA, Leandro Reinaldo da. Identidade e redesignação de gênero: Aspectos... p. 36. 
Evidencia-se ainda que tais questões não se mostram apenas como importantes para um certo grupo de pessoas mas sim se revestem de uma natureza e interesse transnacional, sendo relevante para todo o continente que o respeito às individualidades e características humanas se faça um padrão a ser seguido.

Em que pese a enorme variedade de normas emanadas pelas diversas nações que compõem a Europa é bastante pertinente se considerar que o órgão europeu responsável pela atenção e proteção aos direitos humanos se coloque de forma firme no sentido de fazer com que os países vinculados à Convenção Europeia de Direitos Humanos se adequem a parâmetros preponderantes ao pleno respeito à população trans.

Constata-se o sólido posicionamento da região que em sua grande maioria tem legislação direcionada ao reconhecimento da identidade de gênero, permitindo a realização de mudança do prenome e da designação de gênero nos documentos pessoais do indivíduo. $\mathrm{O}$ que vem ganhando cada vez mais espaço e passa a se tornar uma tendência a ser seguida por todos os países, muito ante a imposição de sua atenção por parte da Corte Europeia de Direitos Humanos, é a proibição da exigência da realização de processo de esterilização prévio por parte do transexual, bem como a vedação da obrigatoriedade da realização de tratamento médico ou apresentação de laudo médico para que se tenha acesso aos benefícios decorrentes do reconhecimento da identidade de gênero.

Não se pode também olvidar a crescente e intensa movimentação no sentido de despatologização da transexualidade, como forma de afastar a estigmatização da pessoa e com isso tentar reduzir o amplo e contínuo preconceito que se mostra tão lesivo ao indivíduo e que acaba por conduzi-lo a uma condição econômica deficitária (face a grande evasão escolar e a restrições no mercado de trabalho), bem como a uma realidade social (permeada por um alto índice de tentativas de suicídio) bastante traumática.

A luta pela garantia do ser humano como o pilar elementar e nuclear da sociedade é primordial para o estabelecimento da cidadania como um lastro para a comunidade europeia e mundial, sendo certo que o respeito a todos tem o condão de fazer com que a humanidade evolua e o mundo se torne um lugar melhor para todos.

\section{Referências bibliográficas}

BLACKLESS, M., CHARUVASTRA, A., DERRYCK, A., FAUSTO-STERLING, A., LAUZANNE, K. and LEE, E. (2000), How sexually dimorphic are we? Review and synthesis. American Journal of Human Biology, vol. 12, p. 151-166, 2000. ISSN 1520-6300

CUNHA, Leandro Reinaldo da. Identidade e redesignação de gênero: Aspectos da personalidade, da família e da responsabilidade civil. Rio de Janeiro: Lumen Juris, 2015. ISBN 978-85-8440-206-9

CUNHA, Leandro Reinaldo da. Identidade de gênero sob a atual perspectiva dos tribunais superiores. a possibilidade da mudança de nome e gênero nos documentos independ- 
entemente da realização de procedimentos cirúrgicos prévios. Revista dos Tribunais: São Paulo, v. 986, p. 111-125, dez. 2017. ISSN 0034-9275

Identidade de gênero e a responsabilidade civil do Estado pela leniência legislativa. Revista dos Tribunais: São Paulo, v. 962 p. 37-52, 2015. ISSN 0034-9275

CUNHA, Leandro Reinaldo da. RIOS, Vinícius Custódio. Mercado transgênero e a dignidade da pessoa humana sob a perspectiva do capitalismo humanista, Revista dos Tribunais: São Paulo, v. 972, p. 165-184, out. 2016. ISSN 0034-9275

MIZRAHI, Mauricio Luis. Homosexualidad y transexualismo. Buenos Aires: Astrea, 2006. ISNB 950-508-709-8

SANTOS, Moara de Medeiros Rocha; ARAUJO, Tereza Cristina Cavalcanti Ferreira de. Desenvolvimento da identidade de gênero em casos de intersexualidade: contribuições da Psicologia. 2006. 246 f. Tese de doutorado em psicologia. Universidade de Brasília, Brasília, 2006

SZANIAWSKI, Elimar. Limites e possibilidades do direito de redesignação do estado sexual: estudo sobre o transexualismo: aspectos médicos e jurídicos. São Paulo: RT, 1998. ISNB 85-203-1667-0

VIEIRA, Tereza Rodrigues. Nome e Sexo - Mudanças no Registro Civil. 2. ed. São Paulo: Atlas, 2012. ISNB978-85-224-7363-2

Artigo Recebido a 20 de fevereiro de 2018 | Aceite a 24 de março de 2018 